\title{
Evaluating the Impacts of Speed Limit Increases on Rural Two-Lane Highways using 2 Quantile Regression
}

3

4

5

6 Md Shakir Mahmud

7 Department of Civil and Environmental Engineering

8 Michigan State University

9 East Lansing, MI 48824

10 E-mail: mahmudmd@msu.edu

Nischal Gupta

Department of Civil and Environmental Engineering Michigan State University

East Lansing, MI 48824

E-mail: guptanis@msu.edu

Babak Safaei

Department of Civil and Environmental Engineering Michigan State University

East Lansing, MI 48824

E-mail: safaeiba@msu.edu

Hisham Jashami

Department of Civil and Environmental Engineering Michigan State University

East Lansing, MI 48824

Email: jashamih@msu.edu

Timothy J. Gates

Department of Civil and Environmental Engineering Michigan State University

East Lansing, MI 48824

E-mail: gatestim@msu.edu

Peter T. Savolainen

Department of Civil and Environmental Engineering Michigan State University

East Lansing, MI 48824

E-mail: pete@msu.edu

Eva Kassens-Noor

School of Planning, Design, and Construction

Michigan State University

East Lansing, MI 48824

E-mail: ekn@msu.edu

Words excluding Tables $=6,258$

Tables: 3 x $250=750$

Total Words $=7,008$

Date Submitted: August 1, 2020 
1 ABSTRACT

2 Understanding speed selection behavior of drivers following speed limits increases is critically 3 important. To date, the literature has largely focused on freeways and the effects of speed limit 4 changes on two-lane highways remains under researched. Prior research has generally focused on 5 changes to mean speeds, though the speeds of both the highest and lowest drivers are also of great 6 interest. This study investigates trends in free-flow travel speeds following 2017 legislation that 7 increased the posted speed limit from 55 to $65 \mathrm{mph}$ on 943 miles of rural highways in Michigan. 8 Speed data were collected for over 46,000 drivers at 67 increase segments where speed limit 9 increased and 28 control segments, where speed limits remained unchanged, before and during 10 each of the two successive years following the speed limit increases. Site-specific traffic, 11 geometric, and cross-sectional information was also collected. Impacts of the speed limit increases 12 on the $15^{\text {th }}, 50^{\text {th }}$, and $85^{\text {th }}$ percentile speeds were evaluated using quantile regression. Separate 13 analyses were conducted for passenger cars and heavy vehicles. Locations where the speed limits 14 were raised experienced increases in travel speeds ranging from 3.8 to $5.1 \mathrm{mph}$. The control sites 15 experienced marginal changes in speeds, which suggests any spillover effects of the higher speed 16 limits have been limited. Significant differences were observed across the quantiles with respect 17 to the effects of the speed limit increases, as well as numerous site-specific variables of interest. 18 The results provide important insights as to the nature of driver speed selection and the impacts of 19 speed limit increases.

21 Keywords: speed limit increase, non-freeways, rural highways, quantile regression 


\section{INTRODUCTION AND BACKGROUND}

The impacts of speed limits on traffic operations and safety have been long-standing areas of interest to transportation policy and research. Maximum statutory speed limits are posted to inform drivers of the highest speed that is considered safe and reasonable under ideal traffic, road, and weather conditions (1). Speed limits also provide a basis for the enforcement of unreasonably high travel speeds.

Speed limits are generally applicable for a particular class of highways with specific design, functional, jurisdictional, or location characteristics (2). These limits are typically established in consideration of the design speed of the road, which influences various geometric design features such as minimum stopping sight distance, minimum horizontal curve radius, and maximum grade (3). The American Association of State Highway and Transportation Officials (AASHTO) recommends using above-minimum criteria where practical (3) and, ideally, the statutory speed limit should be set at or below the highway's prevailing design speed.

Speed limit policies in the United States have changed considerably over time, starting with the implementation of the National Maximum Speed Law (NMSL) of $55 \mathrm{mph}$ in 1974. In 1987, the Surface Transportation and Uniform Relocation Assistance Act allowed for increases of up to $65 \mathrm{mph}$ on rural interstates (4) and the NMSL was fully repealed in 1995, restoring the autonomy of establishing speed limits to the individual states (5). Subsequent to the enactment of these laws, speed limits were predominantly increased on limited-access rural freeways, which are the types of roads with the highest speed limits and are also the safest when considering crash risks per distance traveled (6) given their higher design standards. The research literature shows that fatalities on rural interstates are consistently higher among those states with higher maximum statutory speed limits (7). Despite this fact, at least 25 states have increased or proposed to increase maximum speed limits since $2011(5,8-10)$.

In general, the research literature has focused predominantly on limited access freeways. Some early studies following the 1987 NMSL relaxation found average speeds to increase by 2 to $7 \mathrm{mph}$ following the speed limit increase to $65 \mathrm{mph}(11-14)$. Subsequent studies have shown increases on the order of 2 to $3 \mathrm{mph}$, in general, for 5 -mph increases in the posted limit $(15,16)$. Although speed limit increases generally increase operating speeds, the exact relationship is not straight-forward and several studies demonstrate considerable variability in the magnitude of speed increases after speed limits are changed $(16,17)$. Earlier research has shown drivers' speed selection to be impacted by not only the posted speed limit, but also by roadway and roadside characteristics, as well as traffic volumes (18-22). Design speed, pavement conditions, and weather are some of the other factors that directly impact drivers' speed selection while differences are also observed across vehicle types and among driver with different socio-economic characteristics $(22,23)$.

In contrast, research on the effects of speed limit changes on two-lane highways has been more limited. This is due, in part, to the significant variability in the design characteristics of such highways, where speeds can range from 25 to $75 \mathrm{mph}$. This makes it difficult to assess the magnitude of large-scale speed limit increases across states as has been done frequently in the case of freeways (7). A National Cooperative Highway Research Program (NCHRP) project (15) found that increasing speeds from $55 \mathrm{mph}$ to $65 \mathrm{mph}$ resulted in increases in average speed of $3.4 \mathrm{mph}$ from a before-after analysis. Additional studies have investigated the relationship between roadway geometry and operating speeds, particularly on horizontal curves. The majority of these studies have also focused on freeways (16-20), though a few recent studies have examined speeds on rural two-lane highways $(21,22)$. The research literature shows that increases in speed limits 
significantly affect speeds on two-lane roads, but the results are highly dependent on contextual factors (24).

At least 27 US states have maximum speed limits that are lower on two-lane highways as compared to freeways, while the remaining states provide the same maximum speed limit for both roadway types (25). However, various states have also recently increased the speed limits on these roadways, as well. The safety literature generally suggests that increasing speed limits on nonfreeways will result in an increase in the overall crash rate and will also result in a higher proportion of more severe crashes due to the increase in the energy dissipated during crashes due to vehicles traveling at higher speeds (15). However, further research in this area is warranted given continuing consideration of speed limit increases in both the US and abroad.

Related to this issue, the State of Michigan passed Public Acts 445 and 447 in 2016, which increased the state's maximum statutory speed limits from 55 to $65 \mathrm{mph}$ on more than 900 miles of state-maintained two-lane highways. Moreover, the speed limit for heavy vehicles, including trucks and buses, also increased to $65 \mathrm{mph}$ on these same highways $(26,27)$. Implementation of the speed limit increases began in June of 2017 and concluded later that year. Consequently, this provides an appropriate setting to obtain important insights as to the immediate and longer term impacts on driver speed selection. To that end, this paper presents the results of a longitudinal case-control evaluation that was performed to quantify changes in driver speed selection as a function of speed limit, vehicle type, and various site characteristics.

In addition, this study addresses another gap in the research literature by examining the full speed distribution of vehicles under free-flow conditions. Much of the prior research has investigated impacts on mean speeds, often examining aggregate trends that include trailing vehicles where the driver was not free to select their preferred speed $(9,12,14,15,16)$. Such methods are unable to fully exploit the rich information available in the speed data distributions. For example, the aforementioned NCHRP project (15) utilized daily aggregated average speed measures from permanent traffic recorders as a part of a before-after study, as well as crosssectional data that did not include any data from the period before the speed limit increases occurred.

The speeds at either extreme of the speed distribution are of particular interest as crash risks are significantly increased when there is substantive variability in speeds. To address these concerns, this study involves the estimation of a series of quantile regression models to assess changes in the $15^{\text {th }}, 50^{\text {th }}$, and $85^{\text {th }}$ percentile speeds following the speed limit increases. The results help to advance our understanding of how speed limit increases affect the driving population and how these underlying behavioral changes may help to explain related increases that are observed with respect to crash risks.

\section{DATA COLLECTION AND SUMMARY}

This study evaluates changes in travel speeds along rural two-lane highways maintained by the Michigan Department of Transportation (MDOT). The primary objective is to discern impacts associated with the 2017 statewide speed limit increases. As a part of this effort, a case-control analysis is conducted to compare speeds before and after this increase went into effect. The control locations include highway segments where the 55-mph maximum limit was maintained and allow for a determination of whether any spillover effects are observed where speeds increase at other locations due, in part, to increases occurring elsewhere in the system. In addition, the speed data from all locations are integrated with robust information detailing the roadway and roadside environment, as well as prevailing traffic conditions. This is important as AASHTO notes that 
driving speeds are affected by four general factors, including physical characteristics of the road and roadside interference, weather, other vehicles, and the speed limit (3). This section provides details of the site selection and data collection procedures employed as a part of this study.

\section{Site Selection}

Prior to the speed limit increases in mid-2017, the research team identified locations on the MDOT rural two-lane highway network where periodic spot-speed data collection would be performed before and after implementation of the increased speed limit. This included a sample of locations where the speed limit was set to be increased to $65 \mathrm{mph}$, along with a comparison sample of similar highways where the $55 \mathrm{mph}$ limit would be retained. As the speed limit increases mostly occurred in MDOT's most rural Superior and North regions, the majority of both the speed limit increase and control sites were selected from those areas. Additional control sites were selected from central and southern Michigan to provide representation among other regions where the $55 \mathrm{mph}$ speed limit was retained.

The data collection setup at most locations occurred along straight, flat (i.e., grades less than 2 percent) sections of highway. However, a select group of horizontal curves with advisory speeds below $55 \mathrm{mph}$ were also included as such locations have been shown to exhibit disproportionately high numbers of speed-related crashes. Generally speaking, no more than one site was selected per county along a specific highway route. Figure 1 provides a map of the routes where speed limits were increased to $65 \mathrm{mph}$, in addition to identifying locations where data were collected for both the speed limit increase and control sites.

Data were collected from a total of 95 sites. At each location, spot speed data were obtained from covert roadside locations using either elevated high-definition video cameras or handheld Light Detection and Ranging (LiDAR) speed guns. The sites include 67 locations ( 30 camera sites and 37 LIDAR sites) at which the speed limits were increased, as well as 28 control sites (18 camera sites and 10 LIDAR sites) where the 55-mph limit remained in place. Supplementary sitespecific information was also collected using aerial photography, including details such as lane width, shoulder widths, horizontal curvature, and the presence of no-passing zones or passing relief lanes.

\section{Speed Data Collection}

Three waves of speed data collection were performed as a part of this study. The initial wave occurred during the late spring and summer of 2017 prior to the speed limit increases. Data for the periods after the speed limit increases were collected during late spring and summer of 2018 and 2019. Data were collected between the hours of $8: 30$ am and 6:30 pm on weekdays under clear weather and dry pavement conditions.

For the LiDAR data collection, measurements were obtained from an unmarked vehicle parked on a side street, driveway, or parking area that was not readily visible to motorists on the subject highway segment. Specific attention was given to being covert so as not to impact the speed of approaching drivers. At each site, the targets were to collect 100 speed measurements for passenger vehicles and at least 10 for heavy vehicles in each direction of travel. During data collection, only vehicles with a headway of at least 4.0 seconds were considered in order to reduce potential impacts of platooning. Due to the rural nature of these highways, free flow conditions were typically present during the data collection.

For the data collection with high definition video cameras, the cameras were temporarily installed on a telescoping pole at covert roadside locations. After completion of the field video 
recordings, a team of trained reviewers manually performed a frame-by-frame review of the videos to assess the time required for each vehicle to traverse a fixed distance between known reference markers. Vehicle classification, headway, and hourly volume in the direction of speed data collection during each study period were also recorded. Vehicles were classified as passenger vehicles, passenger vehicles with trailers, truck, single unit, tractor-trailer, motorcycle, farm equipment, or all-terrain vehicle. As the camera dataset included all the vehicles during the observation time, the dataset was filtered to include only vehicle observations with a minimum headway of 4.0 seconds.

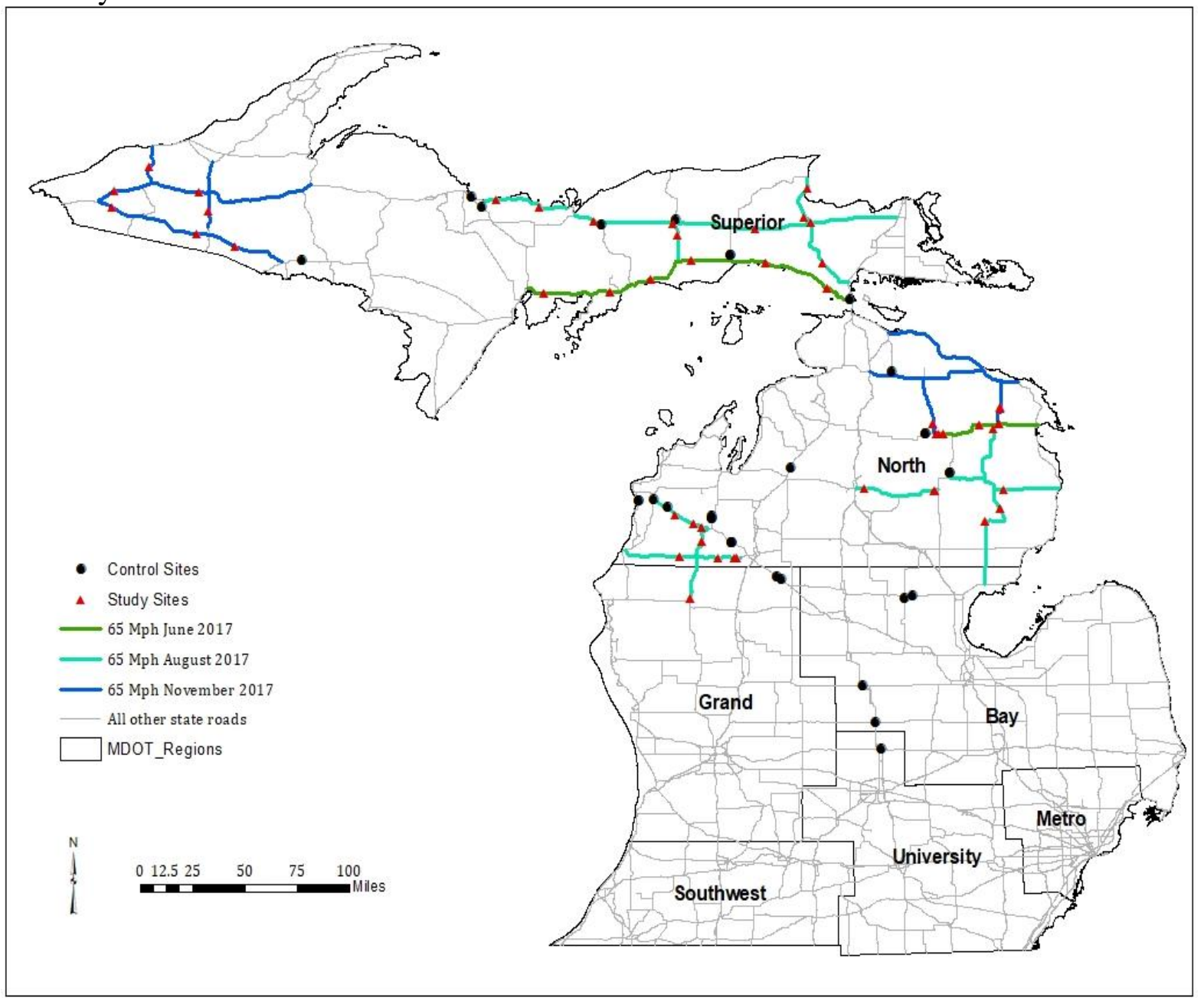

FIGURE 1 Location of Speed Limit Increase and Control Sites for Speed Data Collection.

The collected and calculated data were tabulated and coded into a single data file for subsequent analyses. The initial data set included complete records for 62,939 vehicle observations collected across the three data collection periods from the 95 sites. Prior to the analyses, the dataset was filtered to exclude motorcycles, all-terrain vehicles, farm equipment, passenger vehicles with trailers, and any other observations where free-flow condition could have been compromised (e.g., bicyclist or pedestrian on the shoulder, turning vehicles, passing vehicles, vehicles with brake lights on). Table 1 presents the descriptive statistics for each variable included in the final dataset, which included 46,162 free-flowing vehicles. Site types (increase or control) and data collection period (before or after the speed limit increase) were combined and categorized in four groups to 
test the impact of speed limit change on increase and control segments. Observed vehicles were categorized into passenger cars and heavy vehicles allowing separate analysis for each vehicle types. Sites were also categorized based on the passing permission or presence of passing relief lane on both directions. Roadway geometric characteristics such as lane width and degree of curvature were also used to categorize the collected data. Furthermore, location of the data collection sites in different MDOT regions were also used to categorize collected data.

$7 \quad$ TABLE 1 Descriptive statistics for study sites $(n=46,162)$

\begin{tabular}{|c|c|c|}
\hline Parameters & Mean & Std. Dev. \\
\hline Traffic volume (veh/hr) & 280.00 & 247.84 \\
\hline Before-control sites ( 1 if yes; 0 if no) & 0.13 & 0.33 \\
\hline Before-increase sites ( 1 if yes; 0 if no) & 0.21 & 0.41 \\
\hline After-control sites ( 1 if yes; 0 if no) & 0.24 & 0.43 \\
\hline After-increase sites ( 1 if yes; 0 if no) & 0.42 & 0.49 \\
\hline Passenger vehicle ( 1 if yes; 0 if no) & 0.89 & 0.31 \\
\hline Heavy vehicle ( 1 if yes; 0 if no) & 0.11 & 0.31 \\
\hline Normal section or one-way passing lane ( 1 if yes; 0 if no) & 0.90 & 0.31 \\
\hline Two-way passing lanes ( 1 if yes; 0 if no) & 0.10 & 0.31 \\
\hline Passing permitted ( 1 if yes; 0 if no) & 0.81 & 0.40 \\
\hline Passing restricted ( 1 if yes; 0 if no) & 0.20 & 0.40 \\
\hline Lane width $=12$ feet ( 1 if yes; 0 if no) & 0.74 & 0.44 \\
\hline Lane width $=11$ feet $(1$ if yes; 0 if no) & 0.26 & 0.44 \\
\hline Degree of curvature $=0$ ( 1 if yes; 0 if no $)$ & 0.86 & 0.35 \\
\hline Degree of curvature $<5$ ( 1 if yes; 0 if no) & 0.08 & 0.27 \\
\hline Degree of curvature $=5-10$ ( 1 if yes; 0 if no $)$ & 0.04 & 0.20 \\
\hline Degree of curvature $>10$ ( 1 if yes; 0 if no $)$ & 0.02 & 0.14 \\
\hline MDOT region $=$ Superior $(1$ if yes; 0 if no $)$ & 0.43 & 0.50 \\
\hline MDOT region $=$ Bay $(1$ if yes; 0 if no $)$ & 0.06 & 0.24 \\
\hline MDOT region =North ( 1 if yes; 0 if no) & 0.46 & 0.50 \\
\hline MDOT region $=$ Grand $(1$ if yes; 0 if no) & 0.04 & 0.19 \\
\hline MDOT region $=$ University $(1$ if yes; 0 if no) & 0.01 & 0.11 \\
\hline
\end{tabular}

8

\section{STATISTICAL METHODS}

Using the data described previously, a series of regression models were estimated in order to discern the impacts of the speed limit increases while controlling for the effects of other pertinent factors, including lane width, horizontal curvature, and the presence of passing restrictions and passing relief lanes. Most of the prior studies evaluating impact of speed limit increase utilized aggregated data and compared before-after speed metrics using ordinary least squares (OLS) regression techniques $(16,19,28-30)$, ANOVA, and t-tests (31-33). These methods while were successful proving significant change in speed following the speed limit increases, lacked to provide further details on driver speed selection behavior. While ordinary least squares (OLS) has been the most widely applied method for the analysis of speed data in a regression setting, there are several important limitations to OLS considering the study context. First, speed data tend to be skewed and, as such, the estimates for the conditional mean are not necessarily reflective of the entire speed distribution. Secondly, there is particular interest in the higher and lower quartiles. For example, the $85^{\text {th }}$ percentile is still widely used as a metric for establishing speed limits and, 
as such, changes in this metric are of particular interest. There is also a potential concern as to drivers who are uncomfortable traveling at the highest speeds, which may result in platooning and high-risk passing by other motorists. Quantile regression is an appealing alternative to OLS as this allows for estimation of the entire conditional distribution rather than just the conditional mean. A few prior studies have successfully utilized quantile regression approach to analyze speed data (34, 35). To the best of our knowledge, this is the first study using this technique to evaluate impact of speed limit policy change. For the purposes of this study, the analysis focuses on the $15^{\text {th }}, 50^{\text {th }}$, and $85^{\text {th }}$ percentile speeds. In addition, separate models are estimated for passenger cars and heavy vehicles to determine how speed selection within both groups were impacted by the speed limit increase. Quantile models are similar to OLS linear regression models as they also assume an additive relationship between the dependent variable and the independent variables. However, unlike OLS, quantile regression does not make any assumptions about the distribution of the dependent variable and is more resilient to the influence of outliers (36).

The general form of the quantile regression model is similar to that of a linear regression model. Quantile levels are denoted by $\tau$, which represents the value of the dependent variable below which the proportion of the conditional response population is $\tau$. Within the context of this study, the quantile regression model takes the form shown in Equation 1:

$Q_{\tau}\left(y_{i}\right)=\beta_{0}(\tau)+\beta_{1}(\tau) x_{i 1}+\beta_{2}(\tau) x_{i 2}+\cdots+\beta_{p}(\tau) x_{i p}+\varepsilon_{i}$

where $Q_{\tau}\left(y_{i}\right)$ is the $\tau$ th quantile of the speed distribution, $x_{i j}$ are observed independent variables associated with observation $i$, and $\varepsilon_{i}$ is a random error term with mean equal to zero. The beta coefficients $\beta_{j}(\tau)$ are now the functions of quantile level $\tau$. The $\beta_{j}(\tau)$ parameters are estimated by solving the minimization problem:

$\min _{\beta_{0}(\tau), \cdots, \beta_{k}(\tau)} \sum_{i=1}^{n} \rho_{\tau}\left(y_{i}-\beta_{0}(\tau)-\sum_{j=1}^{p} x_{i j} \beta_{j}(\tau)\right)$

where $\rho_{\tau}(r)=\tau \max (r, 0)+(1-\tau) \max (-r, 0)$. The function $\rho_{\tau}(r)$ is referred to as the check loss which gives asymmetric weights to each of the individual error $r$ for each data point, depending on the quantile and the sign of the error. The function max () returns the maximum value in the parenthesis. Thus, for positive errors, the check function multiplies the error by $\tau$, and by $(1-\tau)$ if the error is negative. Minimizing equation (2) results in minimum median absolute deviation for the quantile model. For each quantile level $\tau$, the solution to this minimization problem yields a distinct set of regression coefficients (37). The quantile regression was conducted using R-Studio in order to estimate a model for the $15^{\text {th }}, 50^{\text {th }}$, and $85^{\text {th }}$ percentile speeds.

The same set of predictor variables were included in each model. This included binary indicator variables for the study period (before vs. after) and site type (increase vs. control), hourly volume during the observation period, lane width, degree of curve, MDOT region, and presence of passing lanes or passing restrictions. Although the dataset included several other variables, including shoulder width and type, terrain, pavement type, and time-of-day, these variables were not found to be statistically significant.

\section{RESULTS AND DISCUSSION}

Figure 2 provides an aggregate-level summary of changes in the average speed, $85^{\text {th }}$ percentile speed, and speed standard deviation for both passenger cars and heavy vehicles at locations where the speed limit increases occurred. This figure provides details for the periods immediately before, 
one year after, and two years after the speed limit increases went into effect and only for the tangent segments (as speeds were significantly different during all periods at the horizontal curve locations).

These preliminary results show the average speeds of passenger cars were $3.8 \mathrm{mph}$ higher after one year and $4.1 \mathrm{mph}$ higher after two years compared to the pre-increase period. For heavy vehicles, these increases were $4.1 \mathrm{mph}$ and $4.5 \mathrm{mph}$, respectively. The $85^{\text {th }}$ percentile speeds increased by $4.0 \mathrm{mph}$ after one year and $5.0 \mathrm{mph}$ after two years for both vehicle types. Importantly, the speed standard deviation (averaged across all sites) also increased following the speed limit increase. This suggests there was significant variability in the magnitude of increases across the distribution of drivers.

It is important to note that these data provide results at an aggregate level and do not consider the effects of traffic volume and geometric characteristics. These factors were considered in the subsequent regression analysis, along with similar data for the control locations.

Period

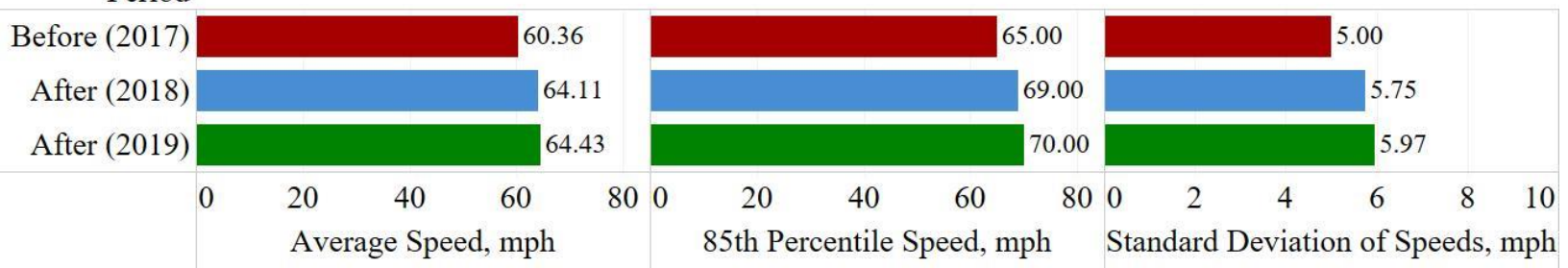

(a) Passenger cars

Period

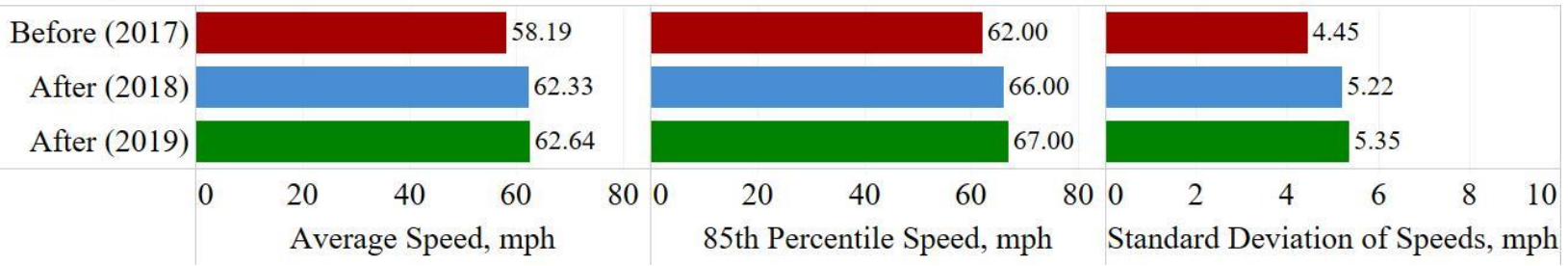

(b) Heavy vehicles

FIGURE 2 Trends in Mean, 85th Percentile, and Standard Deviation of Speeds on Tangent Segments where Speed Limit Increases Occurred

As noted previously, separate quantile regression models were estimated for passenger cars and heavy vehicles at the $15^{\text {th }}, 50^{\text {th }}$, and $85^{\text {th }}$ percentiles (quantiles, $\tau=0.15,0.50$, and 0.85 ). Results of these models are provided in Table 2 and Table 3 for passenger vehicles and heavy vehicles, respectively. For each quantile model, parameter estimates are provided, along with standard errors and the $p$-value that corresponds to the t-statistic used to evaluate whether each of these parameters was significantly different than zero. For each quantile, a separate model and the model equation can be written using the parameter estimates showed in Table 2 . The parameters can be interpreted at different quantile levels separately. For example, at $\tau=0.15$ (15 $5^{\text {th }}$ percentile $)$ if Period and Site Type are set to "After-increase sites", the speed will be $3.78 \mathrm{mph}$ higher than the "Before-control sties". The same will be higher by 5.01 and $4.91 \mathrm{mph}$ at $\tau=0.50$ and $\tau=0.85$, respectively.

For comparison purposes, Figure 3 and Figure 4 provide graphical comparisons of the parameter estimates for each quantile, along with the same estimates for an OLS model of mean speeds for both vehicle types. When examining these plots, the OLS parameter estimates are reflected by a horizontal line, along with the associated 95 percent confidence intervals for each

35 of the OLS parameters. If the quantile regression parameters fall outside of these bounds, it is 
1 reflective of differences that are statistically significant at this same confidence level. It is clear 2 from these respective tables and figures that quantile regression is able to identify relationships in 3 the data that would not be possible under the more typical OLS framework. The remainder of this 4 section details the results of these analyses and provides accompanying discussion of the practical 5 implications of these results.

TABLE 2 Linear Quantile Regression Model for Passenger Vehicle Speeds Dependent Variable $=$ Speed of $\mathrm{PC}(n=41,223)$

\begin{tabular}{|c|c|c|c|c|c|c|}
\hline \multirow{2}{*}{ Parameters } & \multicolumn{2}{|c|}{$\tau=\mathbf{0 . 1 5}$} & \multicolumn{2}{|c|}{$\tau=\mathbf{0 . 5 0}$} & \multicolumn{2}{|c|}{$\tau=\mathbf{0 . 8 5}$} \\
\hline & $\begin{array}{r}\text { Estimate } \\
\text { (Std. Error) }\end{array}$ & $\begin{array}{r}\mathbf{P}- \\
\text { value }\end{array}$ & $\begin{array}{r}\text { Estimate } \\
\text { (Std. Error) }\end{array}$ & $\begin{array}{r}\mathbf{P}- \\
\text { value }\end{array}$ & $\begin{array}{r}\text { Estimate } \\
\text { (Std. Error) }\end{array}$ & $\begin{array}{r}P \text { - } \\
\text { value }\end{array}$ \\
\hline Intercept & $57.72(0.52)$ & $<0.01$ & $63.36(0.35)$ & $<0.01$ & $69.57(0.51)$ & $<0.01$ \\
\hline Ln(Hourly Total Volume) & $-0.84(0.08)$ & $<0.01$ & $-0.84(0.05)$ & $<0.01$ & $-1.03(0.08)$ & $<0.01$ \\
\hline \multicolumn{7}{|l|}{ Period and Site Type } \\
\hline Before-control sites & \multicolumn{6}{|c|}{ Base Condition } \\
\hline Before-increase sites & $1.51(0.17)$ & $<0.01$ & $0.85(0.12)$ & $<0.01$ & $0.27(0.17)$ & 0.12 \\
\hline After-control sites & $-0.78(0.15)$ & $<0.01$ & $-0.35(0.10)$ & $<0.01$ & $-0.25(0.15)$ & 0.09 \\
\hline After-increase sites & $3.78(0.16)$ & $<0.01$ & $5.05(0.11)$ & $<0.01$ & $4.91(0.16)$ & $<0.01$ \\
\hline \multicolumn{7}{|l|}{ Cross-section } \\
\hline Normal/one-way passing & \multicolumn{6}{|c|}{ Base Condition } \\
\hline Two-way passing & $-0.06(0.17)$ & 0.72 & $0.23(0.12)$ & 0.04 & $1.34(0.16)$ & $<0.01$ \\
\hline \multicolumn{7}{|l|}{ Lane Width } \\
\hline 12 feet & \multicolumn{6}{|c|}{ Base Condition } \\
\hline 11 feet & $-0.07(0.12)$ & 0.55 & $-0.28(0.08)$ & $<0.01$ & $-0.21(0.12)$ & 0.07 \\
\hline \multicolumn{7}{|l|}{ Passing } \\
\hline Restricted & \multicolumn{6}{|c|}{ Base Condition } \\
\hline Permitted & $2.05(0.15)$ & $<0.01$ & $1.12(0.10)$ & $<0.01$ & $0.80(0.15)$ & $<0.01$ \\
\hline \multicolumn{7}{|l|}{ Degree of Curvature } \\
\hline 0 & \multicolumn{6}{|c|}{ Base Condition } \\
\hline$<5$ & $-5.28(0.20)$ & $<0.01$ & $-2.46(0.14)$ & $<0.01$ & $-0.77(0.20)$ & $<0.01$ \\
\hline $5-10$ & $-11.50(0.24)$ & $<0.01$ & $-10.69(0.16)$ & $<0.01$ & $-8.07(0.23)$ & $<0.01$ \\
\hline$>10$ & $-25.64(0.34)$ & $<0.01$ & $-27.34(0.23)$ & $<0.01$ & $-15.60(0.34)$ & $<0.01$ \\
\hline \multicolumn{7}{|l|}{ MDOT Region } \\
\hline Superior & \multicolumn{6}{|c|}{ Base Condition } \\
\hline Bay & $-4.52(0.21)$ & $<0.01$ & $-3.51(0.14)$ & $<0.01$ & $-3.24(0.20)$ & $<0.01$ \\
\hline North & $-0.62(0.11)$ & $<0.01$ & $-0.85(0.07)$ & $<0.01$ & $-0.77(0.10)$ & $<0.01$ \\
\hline Grand & $0.61(0.23)$ & $<0.01$ & $0.75(0.16)$ & $<0.01$ & $1.32(0.23)$ & $<0.01$ \\
\hline University & $-3.24(0.40)$ & $<0.01$ & $-2.12(0.27)$ & $<0.01$ & $-1.80(0.40)$ & $<0.01$ \\
\hline
\end{tabular}

\section{Effects of Speed Limit Increase}

First, it should be noted that the sites where the speed limits were increased tended to have higher speeds than the control sections. While the control sites were matched by traffic volume, geometric characteristics, and proximity to the sites where limits were increased, these results were expected, as the prior operating speeds were one of the factors considered in the selection of the segments where speed limits were changed (38). The $15^{\text {th }}, 50^{\text {th }}$, and $85^{\text {th }}$ percentile speeds were $57.7 \mathrm{mph}$, 
$63.4 \mathrm{mph}$, and $69.6 \mathrm{mph}$, respectively when the $55 \mathrm{mph}$ limit was in place (with other parameters set to zero). Prior to the speed limit change, speeds ranged from 0.3 to $1.5 \mathrm{mph}$ higher among passenger cars and 0.16 to $1.45 \mathrm{mph}$ higher among heavy vehicles at the sites where the increases would subsequently occur.

It is interesting to note that these differences were largest for the lowest quartile and smallest for the highest quartile. This suggests that the drivers who tend to travel the fastest also tend to maintain these higher speeds irrespective of other roadway conditions when the speed limit is the same. In contrast, the drivers who travel at lower speeds tend to increase their speeds when conditions are more favorable, as they tended to be at the sites where speed limits were increased. While it is not possible to determine directly from the available data, this may help to explain why crash risks tend to be exacerbated at higher speeds as this subset of drivers seems less apt to reduce their speeds based on contextual factors. This point will arise during subsequent portions of the discussion, as well.
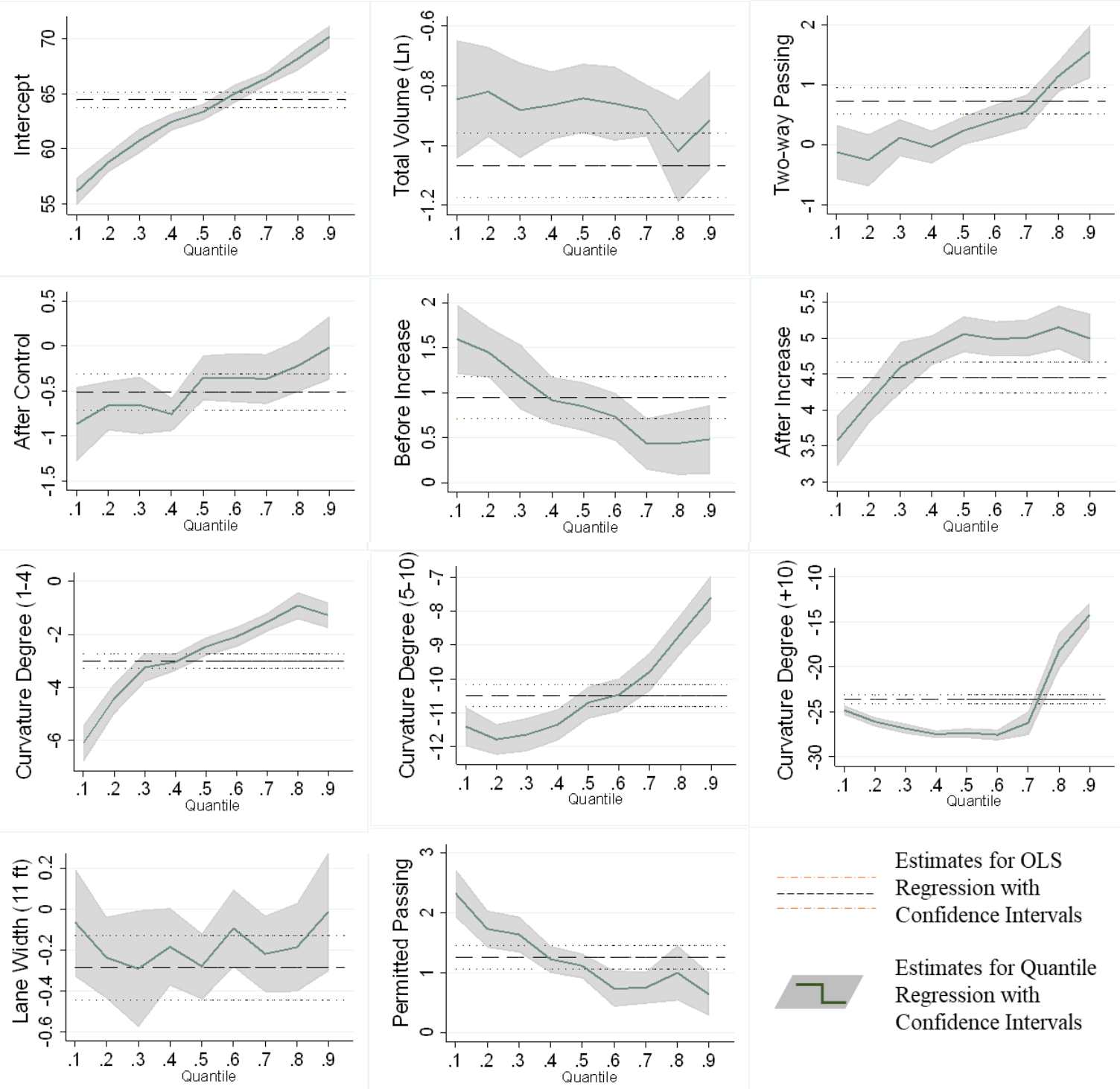

Estimates for OLS Regression with Confidence Intervals

Estimates for Quantile Regression with Confidence Intervals 
Following the speed limit increases, significant increases were experienced across the entire speed distribution at sites where the limits were increased. Among passenger vehicles, these increases were $2.3 \mathrm{mph}, 4.2 \mathrm{mph}$, and $4.6 \mathrm{mph}$ for the $15^{\text {th }}, 50^{\text {th }}$, and $85^{\text {th }}$ percentiles, respectively. The corresponding speed increases for heavy vehicles were $2.5 \mathrm{mph}, 4.3 \mathrm{mph}$, and $4.5 \mathrm{mph}$ for these same percentiles. The increase in speeds was again higher in the upper portion of the distribution (i.e., the $50^{\text {th }}$ and $85^{\text {th }}$ percentile), suggesting that the most aggressive group of drivers tended to increase their speeds by a greater margin.

In general, these results are also similar to findings from prior studies, which have shown that operating speeds increase by roughly half the magnitude of the actual speed limit increase (11, 13-15, 19). Interestingly, speeds either remained unchanged or decreased at the control sites across all quartiles and for both vehicle types. This is in contrast to prior research, which has suggested a potential spillover effect on adjacent roads (39).

TABLE 3 Linear Quantile Regression Model for Heavy Vehicle Speeds

\begin{tabular}{|c|c|c|c|c|c|c|}
\hline \multicolumn{7}{|c|}{ Dependent Variable $=$ Speed of $\mathrm{HV}(\mathrm{n}=4,939)$} \\
\hline & \multicolumn{2}{|c|}{$\tau=\mathbf{0 . 1 5}$} & \multicolumn{2}{|c|}{$\tau=\mathbf{0 . 5 0}$} & \multicolumn{2}{|l|}{$\tau=0.85$} \\
\hline Parameters & $\begin{array}{r}\text { Estimate } \\
\text { (Std. Error) }\end{array}$ & $\begin{array}{r}P \text { P- } \\
\text { value }\end{array}$ & $\begin{array}{r}\text { Estimate } \\
\text { (Std. Error) }\end{array}$ & $\begin{array}{r}\text { P- } \\
\text { value }\end{array}$ & $\begin{array}{r}\text { Estimate } \\
\text { (Std. Error) }\end{array}$ & $\begin{array}{r}P \text { P- } \\
\text { value }\end{array}$ \\
\hline Intercept & $54.35(1.72)$ & $<0.01$ & $61.48(0.96)$ & $<0.01$ & $65.85(1.11)$ & $<0.01$ \\
\hline Ln(Hourly Total Volume) & $-0.73(0.27)$ & $<0.01$ & $-0.90(0.15)$ & $<0.01$ & $-1.03(0.17)$ & $<0.01$ \\
\hline \multicolumn{7}{|l|}{ Period and Site Type } \\
\hline Before-control sites & \multicolumn{6}{|c|}{ Base Condition } \\
\hline Before-increase sites & $1.45(0.58)$ & 0.01 & $0.59(0.32)$ & 0.07 & $0.16(0.38)$ & 0.66 \\
\hline After-control sites & $-0.62(0.50)$ & 0.21 & $-0.65(0.28)$ & 0.02 & $0.17(0.32)$ & 0.60 \\
\hline After-increase sites & $3.95(0.53)$ & $<0.01$ & $4.90(0.29)$ & $<0.01$ & $4.65(0.34)$ & $<0.01$ \\
\hline \multicolumn{7}{|l|}{ Cross-section } \\
\hline Normal/one-way passing & \multicolumn{6}{|c|}{ Base Condition } \\
\hline Two-way passing & $0.20(0.58)$ & 0.72 & $0.29(0.32)$ & 0.36 & $2.05(0.37)$ & $<0.01$ \\
\hline \multicolumn{7}{|l|}{ Lane Width } \\
\hline 12 feet & \multicolumn{6}{|c|}{ Base Condition } \\
\hline 11 feet & $0.95(0.40)$ & 0.02 & $0.20(0.22)$ & 0.36 & $0.69(0.25)$ & $<0.01$ \\
\hline \multicolumn{7}{|l|}{ Passing } \\
\hline Restricted & \multicolumn{6}{|c|}{ Base Condition } \\
\hline Permitted & $2.34(0.47)$ & $<0.01$ & $1.35(0.26)$ & $<0.01$ & $1.16(0.30)$ & $<0.01$ \\
\hline \multicolumn{7}{|l|}{ Degree of Curvature } \\
\hline 0 & \multicolumn{6}{|c|}{ Base Condition } \\
\hline$<5$ & $-7.23(0.71)$ & $<0.01$ & $-3.66(0.40)$ & $<0.01$ & $-1.47(0.46)$ & $<0.01$ \\
\hline $5-10$ & $-12.60(0.72)$ & $<0.01$ & $-12.97(0.40)$ & $<0.01$ & $-10.30(0.47)$ & $<0.01$ \\
\hline$>10$ & $-27.71(1.26)$ & $<0.01$ & $-29.34(0.70)$ & $<0.01$ & $-18.04(0.81)$ & $<0.01$ \\
\hline \multicolumn{7}{|l|}{ MDOT Region } \\
\hline Superior & \multicolumn{6}{|c|}{ Base Condition } \\
\hline Bay & $-4.27(0.70)$ & $<0.01$ & $-2.94(0.39)$ & $<0.01$ & $-2.60(0.45)$ & $<0.01$ \\
\hline North & $0.09(0.34)$ & 0.79 & $0.01(0.19)$ & 0.99 & $0.71(0.22)$ & $<0.01$ \\
\hline Grand & $0.16(0.73)$ & 0.83 & $0.06(0.41)$ & 0.88 & $-0.60(0.47)$ & 0.21 \\
\hline University & $-6.10(1.50)$ & $<0.01$ & $-4.19(0.84)$ & $<0.01$ & $-3.60(0.97)$ & $<0.01$ \\
\hline
\end{tabular}




\section{Effects of Site Characteristics}

2 Turning to the other site characteristics that were found to be related to speed selection, several of 3 the roadway-related variables also showed interesting associations with specific quartiles of the 4 speed distribution. First, speeds were consistently reduced during periods when traffic volumes were higher. Since all of the vehicles included as a part of this analysis included headways of at least 4.0 seconds, this is likely reflective of the relative density of traffic over the course of the segment, including upstream of the speed observation location. This is reinforced by the fact that the speed reductions were most pronounced among the highest quartiles. If these segments tended to experience higher volumes, there is less opportunity for the fastest vehicles to maintain these higher speeds.
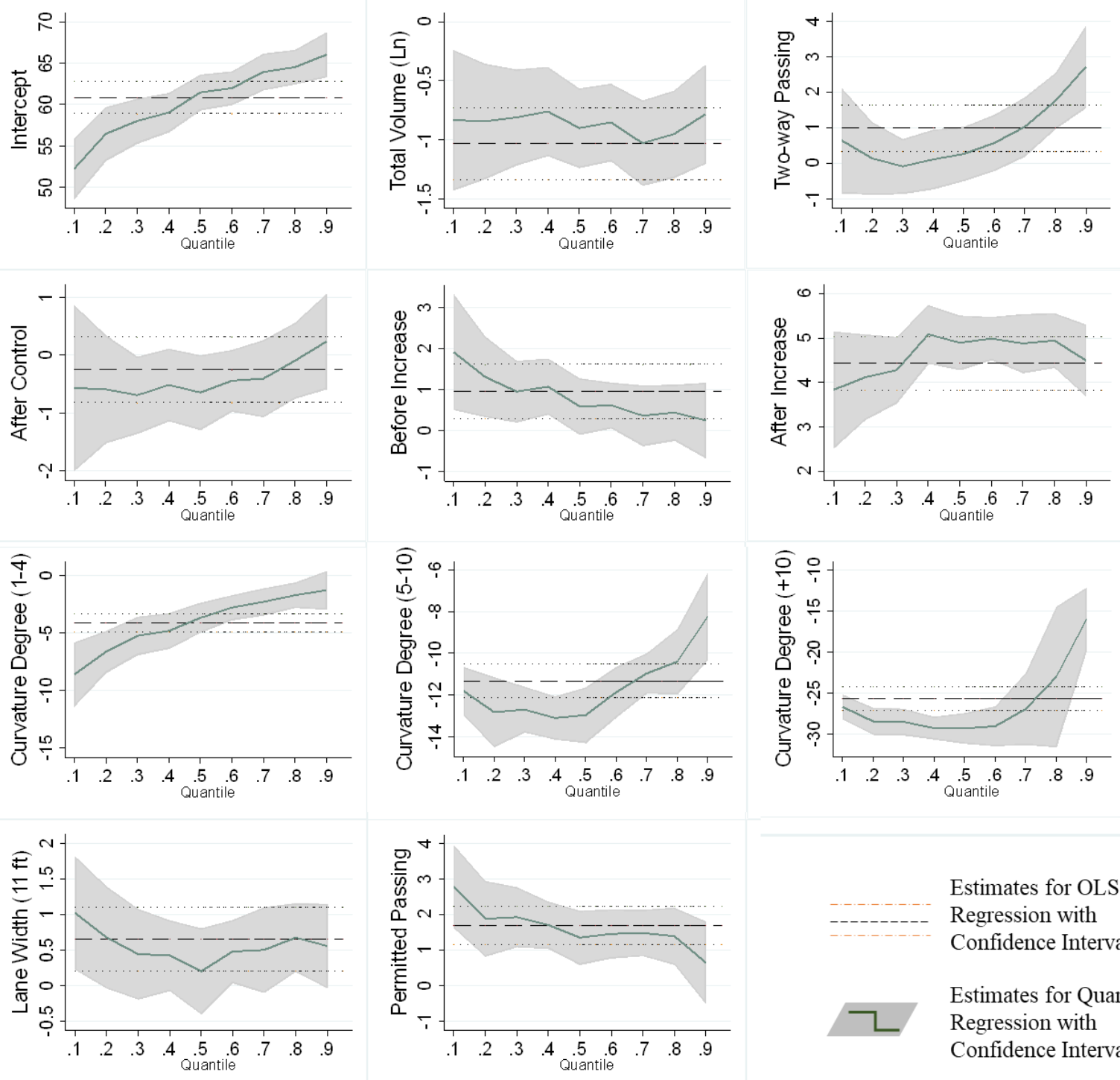

Estimates for OLS Regression with Confidence Intervals

Estimates for Quantile Regression with Confidence Intervals

FIGURE 4 Plot of Parameter Estimates for Speed Quantiles for Heavy Vehicles

Similar findings emerged when considering the effects of geometric and traffic 15 characteristics that related to passing. Speeds tended to be marginally different among the $15^{\text {th }}$ and 
$50^{\text {th }}$ percentiles along four-lane cross-sections, which included passing relief lanes in both directions. However, the $85^{\text {th }}$ percentile speeds were $1.3 \mathrm{mph}$ higher among passenger vehicles and $2.0 \mathrm{mph}$ higher among trucks. This shows that the most aggressive drivers tend to increase their speeds significantly along these extended passing sections.

Related to this same result, two-lane segments where passing was allowed (without passing relief lanes) showed higher speeds across the entire distribution, although the magnitude of this difference was greatest at lower speeds. This reinforces some of the same patterns alluded to previously. The lowest speed drivers appear to adapt their speeds more based upon changes in the driving environment. It is difficult to determine what the causes are for this behavior, though potential explanations may include greater risk aversion among this group or lower levels of comfort under higher stress driving environments. This finding generally aligns with previous results $(18,20,22)$.

One of the most interesting results related to horizontal curvature. There was significant variability in the sharpness of the curves included in the sample of study sites. Each site was classified into one of four groups based upon its degree of curvature, which ranged from 0 (tangent sections), to 5 degrees (radius $=1,146 \mathrm{ft}$ ), to 10 degrees (radius $=574 \mathrm{ft}$ ), or more. For both vehicle types and all quartiles, speeds were consistently reduced as the horizontal curves became tighter. These speed reductions were again consistently greater among the lowest speed quartiles and lower among the highest speed quartiles. On the largest radius (i.e., broadest) curves, the $85^{\text {th }}$ percentile vehicles reduced their speeds by only $0.8 \mathrm{mph}$ and $1.5 \mathrm{mph}$ among passenger vehicles and trucks, respectively. In contrast, speed reductions among the $15^{\text {th }}$ percentile were 5.3 and $7.2 \mathrm{mph}$. These same general trends held for the intermediate radius curves. For the sharpest curves in the sample, reductions among the $85^{\text {th }}$ percentile vehicles were $15.6 \mathrm{mph}$ and $18.0 \mathrm{mph}$ among passenger vehicles and trucks, while these reductions were $25.6 \mathrm{mph}$ and $27.7 \mathrm{mph}$ within the $15^{\text {th }}$ percentile vehicles.

Lastly, lane width had marginal impacts on speed selection. Passenger vehicles reduced their speeds very slightly on 11-ft lanes as compared to $12-\mathrm{ft}$ lanes, with the greatest differences being only $0.3 \mathrm{mph}$. Among heavy vehicles, speeds were actually marginally higher on the $11-\mathrm{ft}$ lanes. Collectively, these results suggest that lane widths do not have a substantive impact on speeds at widths of 11 feet or above. Pronounced differences were also exhibited within several MDOT regions, though these are largely an artifact of the dataset since these regions tended to include a disproportionately large number of control sites and very small numbers of segments where speed limit increases occurred.

\section{CONCLUSIONS}

This study provides important insights into the impacts of speed limit increases on the underlying speed selection behavior of drivers. Spot speed data from 95 study locations provided very highfidelity data as to the speed selection of more than 46,000 drivers under free-flow conditions. This included 67 road segments where speed limits were increased from 55 to $65 \mathrm{mph}$, as well as 28 control sites where the speed limit was a consistent $55 \mathrm{mph}$ over the three-year study period. Three waves of speed data were collected, including shortly before (2017), one year after (2018), and two years after (2019) the increases occurred.

From a big-picture perspective, the results show that the 10-mph speed limit increases resulted in travel speeds that were generally between $3 \mathrm{mph}$ and $5 \mathrm{mph}$ higher across the distributions of both passenger vehicles and large trucks. These findings are largely consistent with prior research and reinforce the fact that drivers adjust their speeds based upon the posted limit 
and to their environments, particularly on two-lane highways. Notably, the travel speed increases varied significantly among drivers: the magnitude of these increases tend to be highest among the top end of the speed distribution. In contrast, the lowest speed drivers increased their speeds by the least amount. This is important from a safety management perspective as these differences in speed selection behavior also tend to increase the variability in travel speeds, helping to explain the increases in the standard deviation in speeds among both passenger vehicles and heavy vehicles following the speed limit increases. For both vehicle types, these increases were generally in the range of 0.8 to $0.9 \mathrm{mph}$.

This increase in variability runs counter to the frequent argument that speed limit increases tend to reduce the variability in speeds, as well as the resultant crash risk. For example most of the previous speed limit increases have been justified with the argument that existing operating speeds on high-speed roadways tend to exceed the posted speed limit anyways, often by significant amounts (40). It would be very interesting to examine how these effects extrapolate to speeds beyond $65 \mathrm{mph}$ or to other facility types, such as limited access freeways.

The magnitude of the changes in speed limits also varied significantly based upon roadway characteristics, including between passing and no-passing zones, along passing relief lanes, and, particularly, on horizontal curves. In each of these instances, a few common trends emerged. When opportunities to drive faster arose, the fastest drivers increased their speeds more so than middle and lower speed drivers. Consequently, an important next step is to determine how these trends in driver speed selection impact safety performance.

Such research would provide important support to inform future speed limit policy decisions. While the $85^{\text {th }}$ percentile speed has historically been viewed as a de facto performance measure for determining appropriate speed limits, a 2018 survey conducted by the National Committee on Uniform Traffic Control Devices (NCUTCD) Task Force shows that those professionals who perform posted speed limit studies rarely use only the 85th percentile speed and, instead, consider the context of the roadway where the speed limit change is being considered (41). This includes factors explicitly noted in the Manual of Uniform Traffic Control Devices (2) that may be considered when establishing or reevaluating speed limits, which include road characteristics, roadside development, and reported crash experiences. Being able to relate differences in speed distributions to these factors has the potential to provide a more robust, quantitatively based analysis framework for selecting appropriate speed limits for specific site conditions.

Lastly, this study appears to be among the first in the traffic safety research literature to exploit the advantages of quantile regression. As clearly demonstrated herein, reliance on OLS regression allows for important insights into impacts on the conditional mean speed of traffic based upon speed limit increases and other site characteristics. However, significant information is lost by considering only the average speed of traffic. Quantile regression is likely to provide valuable insights across a range of other contexts in which there is particular interest amongst the highest and lower quantiles of a distribution.

Lastly, there are several limitations that should be noted with respect to this study. First, quantile regression as applied in this study allows for the investigation of differences in speed selection behavior within the distribution of vehicles observed at specific roadway locations. However, it is important to note that these quantiles do not necessarily represent the speeds of the same drivers across locations. For example, a driver may be in significantly different quantiles across study locations or at the same study location during a different time period. Nonetheless, the consistency of these results across vehicle types and quantiles suggest that important 
relationships do exist. This is an area where naturalistic driving study data, or other similar methods, would be valuable as they would allow for inferences as to various quantiles of interest while controlling for driver-specific effects.

Moving forward, the establishment of maximum speed limits on rural two-lane highways will continue to be an area of substantive interest to researchers, legislatures, and the traveling public. Ultimately, additional research is warranted to fully understand the nature of these relationships. For example, the impacts of emerging concerns, such as distracted driving and the integration of connective and autonomous vehicles, are among the issues that prompt the need for such scrutiny.

\section{DISCLAIMER}

Funding for this research was provided by the Michigan Department of Transportation (MDOT). This publication is disseminated in the interest of information exchange. MDOT expressly disclaims any liability, of any kind, or for any reason that might otherwise arise out of any use of this publication or the information or data provided in the publication. MDOT further disclaims any responsibility for typographical errors or accuracy of the information provided or contained within this publication. MDOT makes no warranties or representations whatsoever regarding the quality, content, completeness, suitability, adequacy, sequence, accuracy or timeliness of the information and data provided or that the contents represent standards, specifications, or regulations.

\section{CONTRIBUTIONS}

The authors confirm contribution to the paper as follows: study concept and design: Timothy Gates, Peter Savolainen, Eva Kassens-Noor, and Md Shakir Mahmud; data collection: Timothy Gates and Md Shakir Mahmud; analysis and interpretation of results: Md Shakir Mahmud, Nischal Gupta, Timothy Gates, Peter Savolainen, Hisham Jashami, and Eva Kassens-Noor; draft manuscript preparation: Md Shakir Mahmud, Nischal Gupta, Babak Safaei, and Peter Savolainen. All authors reviewed the results and approved the final version of the manuscript.

\section{REFERENCES}

1. Forbes, G. J., T. Gardner, H. McGee, and R. Srinivasan. Methods and Practices for Setting Speed Limits: An Informational Report. Federal Highway Administration, FHWA-SA-12004, Washington, DC, 2012.

2. Federal Highway Administration (FHWA). Manual on Uniform Traffic Control Devices for Streets and Highways: 2009 Edition Including Revision 1 Dated May 2012 and Revision 2 Dated May 2012. Washington, DC: US Department of Transportation, FHWA, 2012.

3. American Association of State Highway and Transportation Officials (AASHTO). A Policy on Geometric Design of Highways and Streets. Washington, D.C, 2018.

4. U.S. Congress. Surface Transportation and Uniform Relocation Assistance Act of 1987. 1987.

5. Savolainen, P., T. Gates, E. Hacker, A. Davis, S. Frazier, B. Russo, E. Rista, E. Hacker, B. Russo, and E. Rista. Evaluating the Impacts of Speed Limit Policy Alternatives. Michigan. Dept. of Transportation. Office of Research Administration, 2014, p. 163.

6. National Highway Traffic Safety Administration. Fatality Analysis Reporting System (FARS). $\quad$ http://www-fars.nhtsa.dot.gov//QueryTool/QuerySection/SelectYear.aspx. Accessed May 6, 2020. 
7. Davis, A., E. Hacker, P. T. Savolainen, and T. J. Gates. Longitudinal Analysis of Rural Interstate Fatalities in Relation to Speed Limit Policies. Transportation Research Record: Journal of the Transportation Research Board, Vol. 2514, No. 1, 2015, pp. 21-31. https://doi.org/10.3141/2514-03.

8. Armon, R. Speed Limit Jumps to $70 \mathrm{Mph}$ Monday on Ohio Interstates. Akron Beacon Journal, 2013.

9. Donnell, E. T., B. Hamadeh, L. Li, and J. Wood. 70 Mph Study (FHWA-PA-2016-009-PSU WO 13). Pennsylvania. Dept. of Transportation, 2016.

10. Goble, K. Bills in Eight States Would Alter Speed Limits - Land Line. https://landline.media/bills-in-eight-states-would-alter-speed-limits/. Accessed Jul. 16, 2020.

11. Lynn, C., and J. D. Jernigan. The Impact of the 65 MPH Speed Limit on Virginia's Rural Interstate Highways through 1990. Virginia Transportation Research Council, ed. https://rosap.ntl.bts.gov/view/dot/19302.

12. Ossiander, E., and P. Cummings. Freeway Speed Limits and Traffic Fatalities in Washington State. Accident; analysis and prevention, Vol. 34, 2002, pp. 13-18. https://doi.org/10.1016/S0001-4575(00)00098-1.

13. Upchurch, J. Arizona's Experience With the 65-Mph Speed Limit. Transportation Research Record, No. 1244, 1989, pp. 1-6.

14. Freedman, M., and J. R. Esterlitz. Effect of the 65-Mph Speed Limit on Speeds in Three States. In Transportation Research Record 1281, TRB, National Research Council, Washington, D.C., 1990, pp. 52-61.

15. Kockelman, K. Safety Impacts and Other Implications of Raised Speed Limits on HighSpeed Roads. National Cooperative Research Program, Project 17-23, Washington, D.C., 2006.

16. $\mathrm{Hu}, \mathrm{W}$. Raising the Speed Limit from 75 to $80 \mathrm{Mph}$ on Utah Rural Interstates: Effects on Vehicle Speeds and Speed Variance. Journal of Safety Research, Vol. 61, 2017, pp. 83-92. https://doi.org/10.1016/j.jsr.2017.02.006.

17. Casey, S. M., and A. K. Lund. Changes in Speed and Speed Adaptation Following Increase in National Maximum Speed Limit. Journal of Safety Research, Vol. 23, No. 3, 1992, pp. 135-146. https://doi.org/10.1016/0022-4375(92)90016-3.

18. Dixon, K. K., C.-H. Wu, W. Sarasua, and J. Daniel. Posted and Free-Flow Speeds for Rural Multilane Highways in Georgia. Journal of Transportation Engineering, Vol. 125, No. 6, 1999, pp. 487-494. https://doi.org/10.1061/(ASCE)0733-947X(1999)125:6(487).

19. Gates, T., D. Etroit, P. Savolainen, D. Etroit, J. Finkelman, D. Etroit, A. Davis, D. Etroit, T. Gates, P. Savolainen, J. Kay, J. Finkelman, and A. Davis. Evaluating Outcomes of Raising Speed Limits on High Speed Non- Freeways. No. RC-1609B. Michigan. Dept. of Transportation. Office of Research Administration, 2015, p. 123.

20. Russo, B. J., E. Rista, P. T. Savolainen, T. J. Gates, and S. Frazier. Vehicle Speed Characteristics in States with Uniform and Differential Speed Limit Policies. Transportation Research Record: Journal of the Transportation Research Board, Vol. 2492, No. 1, 2015, pp. 1-9. https://doi.org/10.3141/2492-01.

21. Figueroa-Medina, A., and A. Tarko. Reconciling Speed Limits with Design Speeds. Joint Transportation Research Program, 2004.

22. Savolainen, P. T., T. J. Gates, R. Hamzeie, T. J. Kirsch, and Q. Cai. The Interrelationships between Speed Limits, Geometry, and Driver Behavior. Institute for Transportation, Iowa 
State University, November, 2018.

23. Wali, B., A. Ahmed, and N. Ahmad. An Ordered-Probit Analysis of Enforcement of Road Speed Limits. Proceedings of the Institution of Civil Engineers - Transport, Vol. 171, No. 4, 2018, pp. 225-234. https://doi.org/10.1680/jtran.16.00141.

24. Parker, M. R. Effects of Raising and Lowering Speed Limits on Selected Roadway Sections. FHWA-RD-92-0824, FHWA, U.S. Department of Transportation, January, 1997, p. 175.

25. Insurance Institute for Highway Safety. Maximum Posted Speed Limits by States. https://www.iihs.org/topics/speed/speed-limit-laws. Accessed Jul. 30, 2020.

26. Michigan Legislature - House Bill 5523 (2012). http://www.legislature.mi.gov/(S(c0tdhmzsadkvdpoi5bcwfdyp))/mileg.aspx?page=GetObj ect\&objectname=2012-HB-5523. Accessed on Jul. 16, 2020.

27. Michigan Legislature - House Bill 4425 (2015). https://www.legislature.mi.gov/(S(334ijrulko11v5n5w3vldxmo))/mileg.aspx?page=getobj ect\&objectname=2015-HB-4425\&query=on. Accessed Jul. 16, 2020.

28. Gayah, V. V., E. T. Donnell, Z. Yu, and L. Li. Safety and Operational Impacts of Setting Speed Limits below Engineering Recommendations. Accident Analysis and Prevention, Vol. 121, No. August, 2018, pp. 43-52.

29. Retting, R., and I. Cheung. Traffic Speeds Associated with Implementation of $80 \mathrm{Mph}$ Speed Limits on West Texas Rural Interstates. Journal of Safety Research, Vol. 39, No. 5, 2008, pp. 529-534. https://doi.org/10.1016/j.jsr.2008.08.005

30. N. Enustun, D. Hornbeck, S. Lingeman, A. Yang. Safety Aspects of the $55 \mathrm{mph}$ Speed Limit. TSD 295-74. Michigan Department of Transportation, Lansing, 1974.

31. T.M. Borg. Evaluation of the $55 \mathrm{mph}$ Speed Limit. Purdue and Indiana State Highway Commission Joint Highway Research Program, West Lafayette, 1975.

32. Shirazinejad, R. S., and S. Dissanayake. Analysis of Speed Characteristics Before-AndAfter Speed Limit Change. 2018.

33. Sunanda Dissanayake, and Reza Shirazinejad, Safety Evaluation of Raised Speed Limits on Kansas Freeways, Report No. K-TRAN: KSU-16-3, Kansas Department of Transportation, 2018.

34. Hewson, P. Quantile Regression Provides a Fuller Analysis of Speed Data. Accident Analysis and Prevention, Vol. 40, No. 2, 2008, pp. 502-510.

35. Bel, G., C. Bolancé, M. Guillén, and J. Rosell. The environmental effects of changing speed limits: A quantile regression approach. Transportation Research Part D: Transport and Environment 36 (2015): 76-85.

36. Das, K., M. Krzywinski, and N. Altman. Quantile Regression. Nature Methods. 6. Volume $16,451-452$.

37. Koenker, R. Quantile Regression. Cambridge University Press, 2005.

38. Kay, J. J., T. J. Gates, and P. T. Savolainen. Raising Speed Limits on Rural Highways: Process for Identification of Candidate Nonfreeway Segments. Transportation Research Record, Vol. 2618, No. 1, 2017, pp. 58-68. https://doi.org/10.3141/2618-06.

39. Alhomaidat, F., V. Kwigizile, J. S. Oh, and R. Van Houten. How Does an Increased Freeway Speed Limit Influence the Frequency of Crashes on Adjacent Roads? Accident Analysis and Prevention, Vol. 136, 2020, p. 105433. https://doi.org/10.1016/j.aap.2020.105433.

40. Fitzpatrick, K., P. Carlson, M.A. Brewer, M.A.Wooldridge, S.-P. Miaou. NCHRP Report 504: Design speed, operating speed, and posted speed practices. Transportation Research 
1 Board of the National Academies, Washington, D.C., 2003, pp. 103.

2 41. Fitzpatrick, K., R. McCourt, and S. Das. Current Attitudes among Transportation 3 Professionals with Respect to the Setting of Posted Speed Limits. Transportation Research 4 Record: Journal of the Transportation Research Board, Vol. 2673, No. 4, 2019, pp. 778$5 \quad$ 788. https://doi.org/10.1177/0361198119838504. 